\title{
Major Issues in Business Process Management: Key Concerns presented in Academy from a Brazilian Perspective
}

\author{
Valdemar T. F. Confort \\ Univ. Federal do Estado do Rio de \\ Janeiro \\ Av. Pasteur, 458, Urca \\ Rio de Janeiro, RJ, Brazil \\ valdemar.confort@uniriotec.br
}

\author{
Flávia Maria Santoro \\ Univ. Federal do Estado do Rio de \\ Janeiro \\ Av. Pasteur, 458, Urca \\ Rio de Janeiro, RJ, Brazil \\ flavia.santoro@uniriotec.br
}

\begin{abstract}
This paper is part of a major research in Business Process Management (BPM). There are international publications that identify the evolution of this area and practical challenges in several perspectives. This paper contributes with a comprehensive survey that identifies, from a Brazilian perspective, the evolution of the academic interest and the practical challenges of the national organizations. The expected results are, first, that this work can provide evidences to answer our research question: What are the issues BPM in Brazil? In addition, we expect to contribute with an approach and instruments that can be applied in the future in a new evaluation, following the same process of this research. This first part presents the results of a key concerns classification of all the papers presented in a Brazilian's Conference: the Workshop of Business Process Management. With this first part, we aim to contribute by showing and discussing what are the academy keys concern and compare it with the BPM International Conference.
\end{abstract}

\section{Categories and Subject Descriptors}

J.1 [Computer Applications]: Administrative Data Processing

H.4 [Information Systems]: Information Systems Application

H.3.5 [Information Systems]: Information Storage and Retrieval - Online Information Services

D.2 [Software]: Software Engineering

\section{General Terms}

Management, Measurement

Keywords

Business Process Management, BPM

Permission to make digital or hard copies of all or part of this work for personal or classroom use is granted without fee provided that copies are not made or distributed for profit or commercial advantage and that copies bear this notice and the full citation on the first page. To copy otherwise, or republish, to post on servers or to redistribute to lists, requires prior specific permission and/or a fee.

SBSI 2015, May 26-29, 2015, Goiânia, Goiás, Brazil.

Copyright SBC 2015.

\footnotetext{
${ }^{1}$ Chief Executive Officer

${ }^{2}$ Chief Operating Officer

${ }^{3}$ Chief Purchasing Officer
}

\section{INTRODUCTION}

Dumas et al [1] defined Business Process Management (BPM) as the art and science of overseeing how work is performed in an organization to ensure consistent outcomes and to take advantage of improvement opportunities. [1] For Aalst et al [2] [3], BPM combines knowledge from information technology and knowledge from management sciences and applies this to operational business process. [2] [3] Research in this field resulted in a plethora of methods, techniques and tools to support the design, enactment, management and analysis of operational business process [2].

Dumas et al [1] define business processes as a set of inter-related events, activities and decisions points with actors and objects that lead to a result with value for at least one client. BPM concerns to various groups in an organization, from people in charge of the company affairs $\left(\mathrm{CEO}^{1}, \mathrm{COO}^{2}, \mathrm{CPO}^{3}, \mathrm{CIO}^{4}, \mathrm{CFO}^{5}\right.$, and $\left.\mathrm{HR}^{6}\right)$ to people that are part of the processes and responsible for the activities execution.

Since academy and organizations have a mutual interest in BPM, researchers recognize the practical challenges and agree with the increasing of the complexity and the scope of the processes in organizations [2] [4] [5] [6] [7]. Recker presents important evidences of the organizations concerns [8]. First, BPM is a challenge for expert managers [9]; second, in 2009, WinterGreen predicted that BPM market would triplicate in 2009-2014 over US\$ 6.2 billion dollars [10]; finally, organizations deal with initial and trivial stages like discover and document their business process. [11].

Some initiatives contribute to condense the evolution of the knowledge in the BPM field. From an international and academic perspective, Aalst discussed this evolution in the International Conference in BPM from 2003 to 2012 [12]. In this work, he presents a key concern classification and the evaluation of all the 289 papers presented in the editions of that conference.

From 2007 to 2014, Brazil also had its national BPM conference, called Workshop in Business Process Management (WBPM) [13] [14] [15] [16] [17] [18] [19] [20]. Given the similarity, in this paper we intend to answer the question: "What are the issues in BPM from the Brazilian perspective?" in a comprehensive survey, why not start from this evaluation?

\footnotetext{
${ }^{4}$ Chief Information Officer

${ }^{5}$ Chief Financial Officer

${ }^{6}$ Human Resources
} 
In this research, which is part of a major one, we investigate the following question: What are the major key concerns in Brazilian academy?

Therefore, we started studying the key concerns classifications proposed by Aalst [12] [21]. Then, we collected and tagged all the 66 papers from the WBPM. Finally, we evaluated the results and compared with the BPM International Conference.

Besides this introduction, Section 2 presents related work. Section 3 provides the key concerns definitions. Section 4 discusses the results. Section 5 concludes the paper with an outlook from a Brazilian perspective and presents the next steps of this comprehensive survey.

\section{RELATED WORK}

Business Process Management is a well-researched area. Therefore, some papers are remarkable, because they condense those researches and provide an overview of the whole area. In 2003, Aalst, Hotsfede and Weske published a paper with these characteristics. They historically contextualized the rise of business processes management systems (BPMS), presented the fundamentals concepts of the BPM lifecycle, discussed about methodology and modelling, and the rising technology. [2]

In 2013, Aalst published a new survey. A comprehensive survey that starts with the presentation of historical aspects again and then presents a classification schema of BPM research in two perspectives: use cases perspective and key concerns. He classifies the whole papers of BPM International Conference from 2003 to 2012 and the edited book Business Process Management: Models, Techniques, and Empirical Studies [22] in these two perspectives, discusses the results looking backward based on the frequency of each classification, and previews the forwards. [12]

From a Brazilian perspective, to our best knowledge there is no publication that presents such an overview of academic research in BPM. However, an important aspect is that, in Brazil, there was a National Academic Conference. The format was a Workshop held on in conjunction with the Brazilian Symposium in Information System, besides the main track. There were eight workshop editions from 2007 to 2014 with 66 papers published. Therefore, this is the first national research that we have noticed, and it is based on Aalst work characteristics.

\section{THE SIX KEY CONCERNS}

Aalst [12] recognizes that the use cases and key concerns classification provides a survey of the state-of-the-art in BPM research and the analysis of past BPM conferences help to understand the trends in this discipline. According to this author the uses cases perspectives refer to practical and/or intended use of BPM techniques and tools. This perspective, which is valuable for engineering or management, could not require additional BPM research. Moreover, some use cases require foundational research so they are not yet found frequently. Hence, we decided to start this state-of-art research from the key concerns perspective.

Aalst identified six key concerns before the tagging work: process modeling language, process enactment infrastructure, process model analysis, process mining, process flexibility and process reuse [12] apud [21]. We remark that Aalst considers other three potentially missing concerns: process integration, patterns and collaboration. Since, this classification was not used by him, and for a better baseline of comparison, we only classified the papers in the same six key concerns.

Moreover, we aimed to follow the same comparison base, i.e., we tagged as process enactment infrastructure the papers concerned with web services and other integration technologies. If the papers key concern is about patterns, we tag as process modeling languages. The missing concern collaboration could lead to process modeling language, process enactment infrastructure or process model analysis. Let's present the key concerns.

\subsection{Process Modeling Language}

This concern is about the process modeling language to be used. A plethora of notations and extensions of the existing ones have been proposed for modeling workflows and business process. There are a lot papers published to evaluate these notations. Their requeriments are competitive, e.g., a modeling language should be expressive and simple [21] apud [23].

However the intention of the modelling language are quite different. Laguages that aim to automate a process execution (e.g.,BPEL) may be different from languages that aim to be used for documentation (e.g. EPC). There are also languages that are adapted for verification (e.g., WF-nets) or process mining (e.g., Cnets or hidden Markov Chains). Since, the modeling and analysis of process are a central concern in BPM, therefore, the langugage to represent an organization's processes is essential " [12].

\subsection{Process Enactment Infrastructure}

The process enactment infrastructure is a concern about the creation of an infrastructure to execute, support and monitor processes. Aalst give examples like workflow engines, service-oriented computing, interoperability, cloud computing, enterprise application integration, and work distribution systems [21].

The reference model proposed by the Workflow Management Coalition (WfMC) in the early 1990 [24] [25] for outdate standards and technologies is still adequated to the expected funcionality of a WFM/BPM system. Figure 1 presents a BPM reference architecture. The remarkable difference from the WfMC reference model is the detailment of the data sets and the lists of roles of the various stakeholders. The designer uses design tools to create models and organizational structure. The managers is responsible for monitoring the flow of work and, when necessary, he acts. The worker(s) perform the tasks offered by the enactment service. The enactment services, driven by the models and by the organizational data, may launch various kinds of applications to support the execution of the tasks [12].

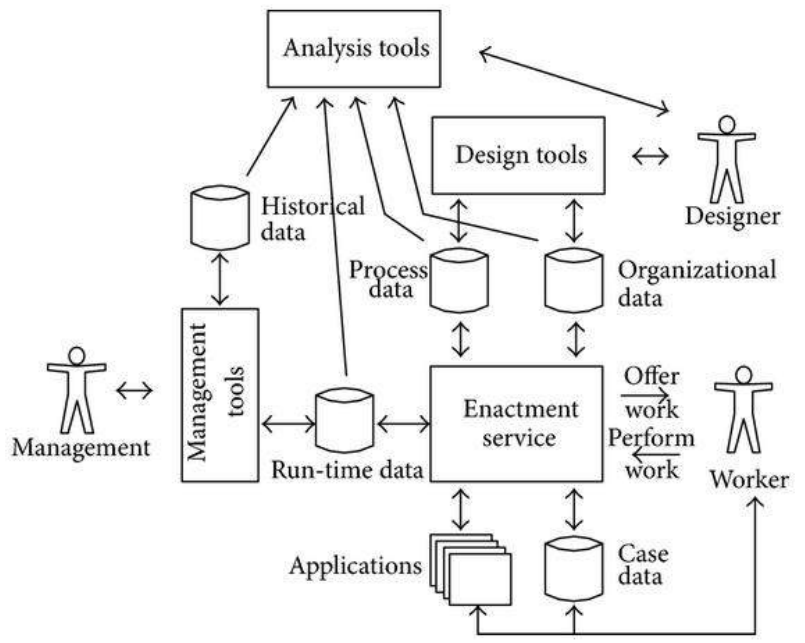

Figure 1. BPM reference architecture [12]

Another important technology in process enactment infrastructure is the Service-Oriented Computing (SOC). The service orientation 
is an approach where the key idea is to subcontract work to specialized service in a loosely coupled fashion. While SOC encapsulates business funcionalities in business applications inside web services, that can be invoked by applications, in ServiceOriented Architecture (SOA) services interact by exchanging messages, for example.

Functional and nonfunctionals requirements need to be considered when implementing a process-aware information system. Workflow patterns [23] can help the designers to elicit functional requirements. Cloud computing and technologies like $\mathrm{SaaS}^{7}, \mathrm{PaaS}^{8}$, and Iaas ${ }^{9}$ are now available to help researchers and practioners with perfomance issues. However, it implies in new challenges related to security concerns.

\subsection{Process Model Analysis}

The process model analysis concern refers to the analysis of processes based on models without using event data. Examples of papers that address this concern are the ones which deals with soundness verification, simulation, and model checking [21].

Verification and perfomance analysis are the mainstream approaches. While verification confirms the correctness of a system or a process, perfomance analysis measures flow times, waiting times, utilization and service levels [12].

Three dimensions of performance are most common: time, cost, and quality. Different Key Performance Indicators (KPIs) can be defined for each dimension. Simulation is a tecnhique, for example, to "optimize" a model given a particular performance indicator [12].

Finally, Aalst [12] remarks that verification and performance analysis relies on the availability of high-quality models. The model-based analysis make sense when the models and reality are aligned. It's the problem of lack of aligment between handmade models and reality.

\subsection{Process Mining}

The process mining refers to analysis techniques that are driven by event data. Process discovery techniques that construct a model based on those event data, conformance checking, extension [21] apud [26] are examples of subjects of this concern.

Aalst [21] remarks that conformance checking can be used to check if reality, wich is recorded in the event log, conforms to the model and vice versa. Hence, conformance checking is an example of how these concerns can help to address the problem of the lack of alighnment between handmade models and reality.

The main objective of process mining is to use event data recorded by system in general to extract process-related information. Discover a process model by observing the event log and check conformance of a given model by comparing it with the reality expressed by the event log are examples of process mining [12].

Figure 2 shows the process mining framework [12] apud [26]. Event data can be classified as "premortem" and "postmortem" event logs. "Postmortem" is the event data with information of completed cases. "Premortem" is the event data of cases that have not yet completed. In "alive" cases it is possible to explore the case information to ensure the correct or efficient handling of the case.

\footnotetext{
${ }^{7}$ Software as a Service

${ }^{8}$ Platform as a Service
}

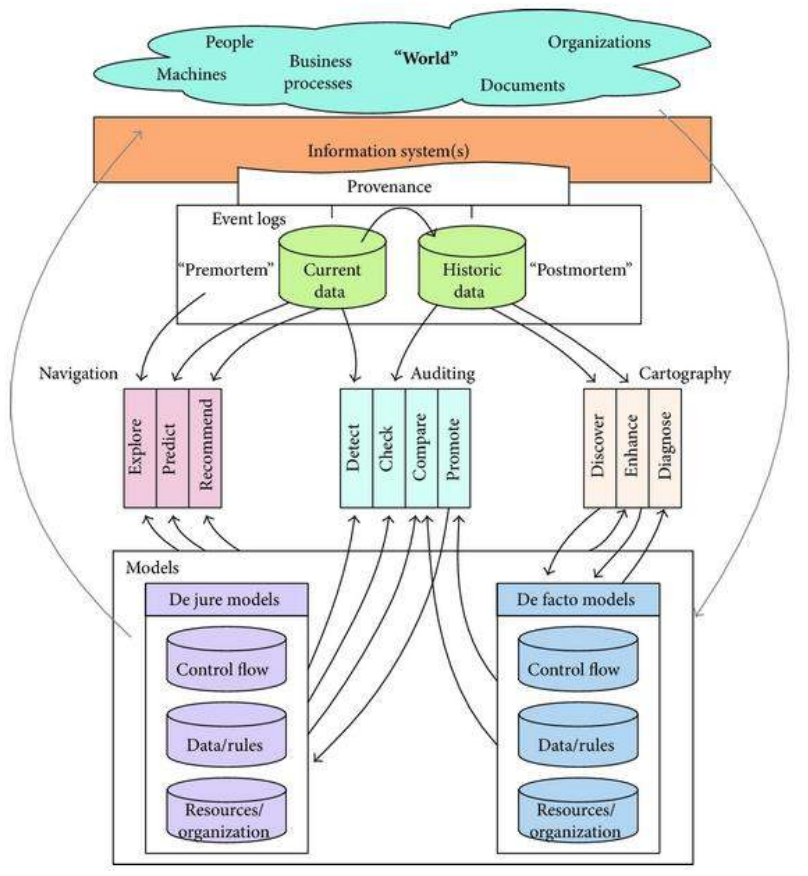

Figure 2. Overview of the process mining spectrum [12]

Postmortem event data are most relevant for tasks related with discovery, enhancement or diagnostic of a process. Premortem event data are most relevant for tasks related with exploration, prediction or recommendation. A mixture of premortem and posmortem data are most relevant to auditing tasks, where the information of both "de jure models" and "de facto models" is necessary. De jure models is normative, i.e., it specifies how things should be done [12]. De facto models is descriptive and aims to capture reality.

Therefore, process mining is not only about process discovery. Process mining can promote analysis through a large spectrum of model analysis tasks and has the event $\log$ as its fundamental part.

\subsection{Process Flexibility}

This concern leads to the problem of a WFM/BPM system beeing inflexible [21]. Flexibility, in the process context, is the ability to deal with both foreseen and unforeseen changes, by varying or adapting those part of the business process that are affected by them, while retaining the essential format of those parts that are not impacted by the variation [21] apud [27]. Case handling [28], adaptive workflows [29], late-binding [30], declarative languages [31] are examples of flexibility papers.

Flexibility can be classified in four types: flexibility by definition, flexibility by deviation, flexibility by underspecifictions, and flexibility by change [12] apud [32].

Flexibility by definition, in design time, is the ability of incorporating an alternative execution path given a process definition, i.e., the most appropriate executuion path can be made at runtime for each process instance. Aalst affirms that all BPM systems support this type of flexibility but declarative language make it easier to defer choices to runtime.

\footnotetext{
${ }^{9}$ Infrastructure as a Service
} 
In flexibility by deviation, a process instance deviates, at runtime, from the execution path prescribed by the original process without altering the process definition itself. To deal with a model that does not contain sufficient information to allow it to be executed to its completion, the ability necessary is the flexibility by underspecification. Finally, when it's necessary to modify the process definition at run time and bring one or all currently executing process instance to the new process definition, we use the ability definied by flexibility by change.

\subsection{Process Reuse}

The last concern refers to the problem that (parts of) processes are often "reinvented" rather than reused [21]. Aalst [12] describes the actual scenario as composed by organization that has hundreds or thousands of process models and deals with problems of maintaining these models. Outdate models, duplicated parts, different models for similar processes or even identical processes are examples of such problems.

However, this is a concern that is gaining more attention by researchers [33]. To deal with this concern, it is necessary process model repositories and tools that allows easy storage and retrieval of these process models.

The features that should be provided arerelated to analysis, management and usage of this large set of process models storaged in process model repository. Figure 3, shows the main activies related to the management of large process model collections.

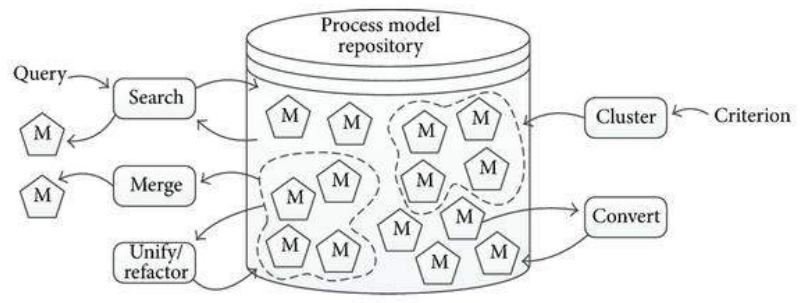

Figure 3. Overview of the main activities related to the management of large model collections [12]

Search is the activity where, given a query, a set of models is returned. In merge activity a set of models is combined into a single model where the behavior of the original models is preserved (in large). Cluster is the activity responsible to identify a set of related process models and may be used as input for merging, for example. Unify/Refactor is an activity that given a set of models as input provides an improvement by aligning them, removing redundancies and applying conventions. Finally, the activity convert, is related to the various mappeing from one notation to another notation.

\section{BRAZILIAN STATE-OF-ART}

In Brazil, BPM is generally associated with the Information Systems area. Similar to the BPM International Conference, there was a premier Conference in a Workshop format in conjunction with the Brazilian's Information Systems Symposium (SBSI), the Workshop in Business Process Management (WBPM). The Symposium is in its $11^{\text {th }}$ edition [32] and the Workshop had the last edition, the $8^{\text {th }}$, in last year (2014) [20]. This year, 2015, BPM was incorporated as a Special Track inside the Symposium.

\subsection{Evolution of Key Concerns in WBPM Conference}

Following Aalst's work, first we collected all the papers published in the WBPM from 2007 to 2014. There were 66 papers published. Then, to evaluate the relative importance of the key concerns, we tagged all the papers. Most papers were tagged with one dominant key concern, but in some cases, more tags were used. In the International Conference, Aalst used 342 tags to evaluate the key concerns of the 289 papers published, a 1.18 tag per paper on average. Our evaluation used 79 tags for the 66 papers published WBPM, 1.19 tags per paper on average. We remark that the proximity of the average was a coincidence, noticed after tagged all the papers.

As an example of paper that can be tagged with more than a dominant key concern we mention the [33]. In fact, this paper presents and discusses the requirements of a tool that could support workflow activity patterns. In this sense, this paper can be tagged as process enactment infrastructure. However, to implement this proposal, it was necessary a statistic repository of activity patterns. Hence, it also can be tagged as process reuse, because it deals with a repository where process models are storage and retrieved. It's not impossible to argue that this paper can be also tagged with process modeling language, because it has a discussion about BPMN 1.2 and UML 2.0 as well as process mining since they have "implemented a process model mining tool to be used for identifying the activity patterns co-occurrences".

We consider the relative frequency here as an indicative of the relative importance of a key concern. We understand from Aalst's work [12] that the concept of relative importance is not only related to the relative frequency of a key concern in papers of the International Conference, but also to the fact of this conference represents "the premier conference in the field". Since we also consider that WBPM is the premier Brazilian's research conference in the field, when we use the term relative importance, as Aalst's work, we are considering these two points.

The relative frequency can be calculated by simply counting the number of tags per key concern and year. For example, for WBPM 2009 four papers were tagged with the key concern process enactment infrastructure. The total number of tags was 17 for the 13 papers published. Therefore, the key concern process enactment infrastructure has a relative frequency of $4 / 17=0.235$. Table 1 shows all relative frequencies of key concerns per year. The last row is the average relative frequency of each key concern over all eight WBPM editions. All rows add up 1. Figure 4 graphically presents the total average.

Table 1. Relative importance of key concerns in eight years of WBPM.

\begin{tabular}{|c|c|c|c|c|c|c|}
\hline Year & 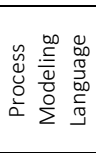 & 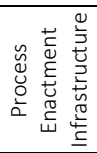 & 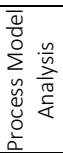 & 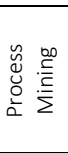 & 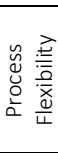 & 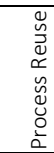 \\
\hline 2007 & 0.07 & 0.33 & 0.27 & 0.13 & 0.13 & 0.07 \\
\hline 2008 & 0.40 & 0.00 & 0.30 & 0.30 & 0.00 & 0.00 \\
\hline 2009 & 0.24 & 0.24 & 0.29 & 0.00 & 0.12 & 0.12 \\
\hline 2010 & 0.00 & 0.25 & 0.63 & 0.00 & 0.00 & 0.13 \\
\hline 2011 & 0.00 & 0.20 & 0.30 & 0.20 & 0.00 & 0.30 \\
\hline 2012 & 0.25 & 0.00 & 0.75 & 0.00 & 0.00 & 0.00 \\
\hline 2013 & 0.20 & 0.00 & 0.40 & 0.20 & 0.20 & 0.00 \\
\hline 2014 & 0.30 & 0.30 & 0.30 & 0.00 & 0.10 & 0.00 \\
\hline Average & 0.18 & 0.20 & 0.35 & 0.10 & 0.08 & 0.09 \\
\hline
\end{tabular}




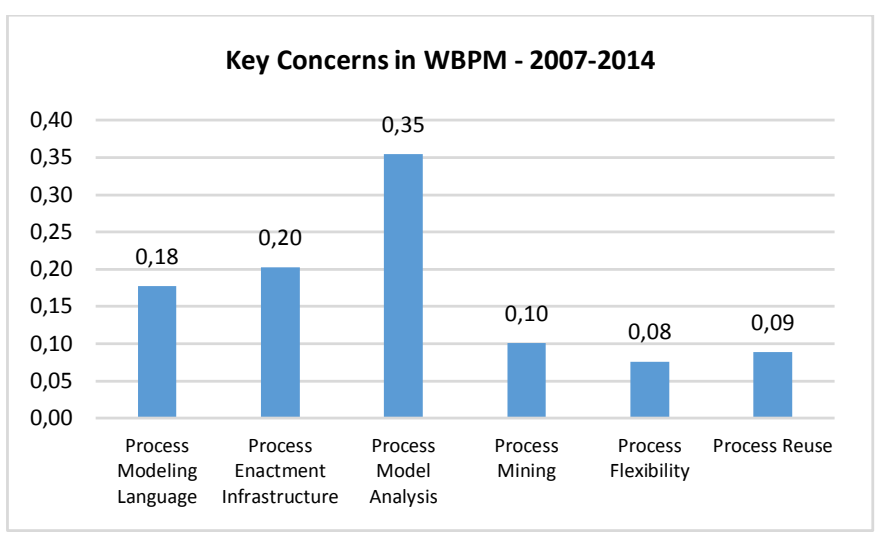

Figure 4. Average relative importance of key concerns in WBPM.

As in Aalst works [12], we noticed the tagging of key concerns is highly subjective. He mentioned, "It is unlikely that two BPM experts would use precisely the same tags for all papers". Moreover, we have the same difficult with broad papers. For, example, what is the key concern classification of this paper? To reduce this subjectivity, before the final tagging, each author made a blind tagging, i.e. each author classified the papers without see the other's classification. Moreover, one of the authors, the most expert, tagged the papers based only in its title. Nevertheless, in the large, the raw results lead to same concerns. Figure 5 shows the raw results of this title classification.

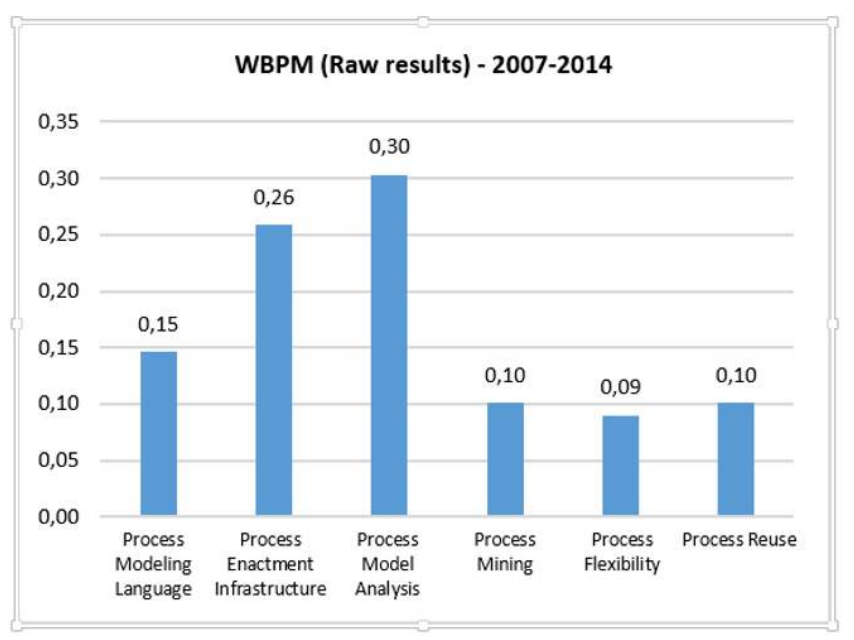

Figure 5. Raw results with the average relative importance verify the subjective component of the classification.

The analysis of key concerns in WBPM shows that the first three key concerns are the most frequent. In comparison, the International Conference has also these three key concerns in the top concerns as shown in Figure 6. We also noticed that they represent more than $70 \%$ of the relative importance in both scenarios, WBPM and International Conference. However, the distribution between the three concerns is quite different. In International Conference, they represent almost one third each one, but in WBPM the process model analysis represents almost the half.

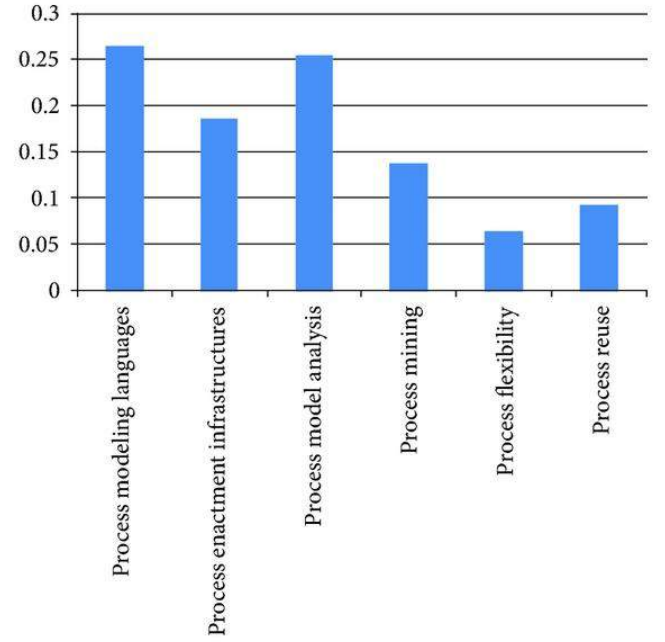

Figure 6. Average relative importance of key concerns in International Conference [12].

It's important to highlight that in the comparison related to time distribution, we observe a two-year shift, since Aalst analysis didn't address 2012, 2013 and 2014 editions of the Internationals Conference. Moreover, Aalst deals with ten years and WBPM had only eight editions. Therefore, we now take a look over the years.

Aalst's results indicate the concerns process mining and process reuse have been gaining importance. In the other hand, the relative frequency of the concern process flexibility is decreasing. Table 2 shows the relative importance of concerns over the years in International Conference and Figure 7 shows the importance of each concern plotted over the time.

Table 2. Relative importance of key concerns in International BPM Conference [12].

\begin{tabular}{|c|c|c|c|c|c|c|}
\hline Year & 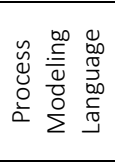 & 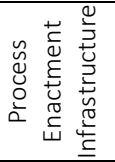 & 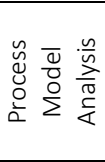 & 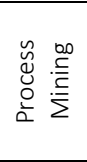 & 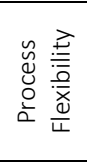 & 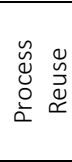 \\
\hline 2000 & 0.355 & 0.161 & 0.290 & 0.000 & 0.161 & 0.032 \\
\hline 2003 & 0.325 & 0.200 & 0.250 & 0.050 & 0.075 & 0.100 \\
\hline 2004 & 0.286 & 0.238 & 0.238 & 0.143 & 0.048 & 0.048 \\
\hline 2005 & 0.288 & 0.231 & 0.212 & 0.058 & 0.096 & 0.115 \\
\hline 2006 & 0.154 & 0.308 & 0.288 & 0.096 & 0.077 & 0.077 \\
\hline 2007 & 0.387 & 0.097 & 0.194 & 0.194 & 0.065 & 0.065 \\
\hline 2008 & 0.324 & 0.108 & 0.297 & 0.135 & 0.081 & 0.054 \\
\hline 2009 & 0.148 & 0.111 & 0.370 & 0.222 & 0.037 & 0.111 \\
\hline 2010 & 0.240 & 0.240 & 0.200 & 0.160 & 0.000 & 0.160 \\
\hline 2011 & 0.143 & 0.171 & 0.200 & 0.314 & 0.000 & 0.171 \\
\hline Average & 0.265 & 0.187 & 0.254 & 0.137 & 0.064 & 0.093 \\
\hline
\end{tabular}




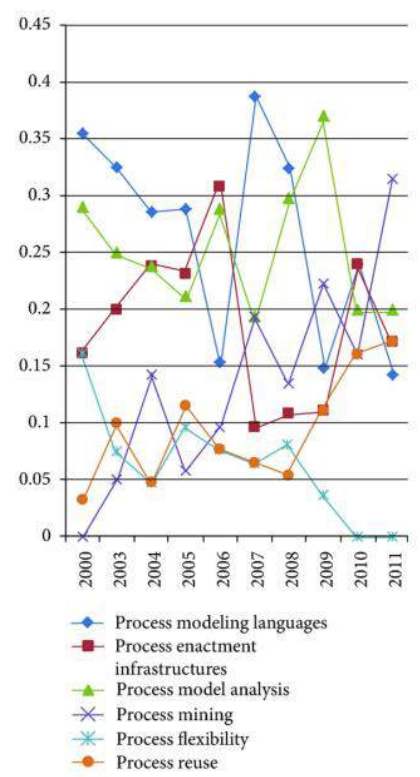

Figure 7. Importance of each concern plotted over the time in International Conference. [12]

Our analysis did not indicate a consistent trend in the sense of a key concern gaining importance and other loosing. Over the years, it is remarkable that process reuse disappeared in the last three years and the process model analysis has always remained. Table 1, shown earlier, presents the relative importance of concerns over the years in WBPM. Figure 8 shows the importance of each concern plotted over the time.

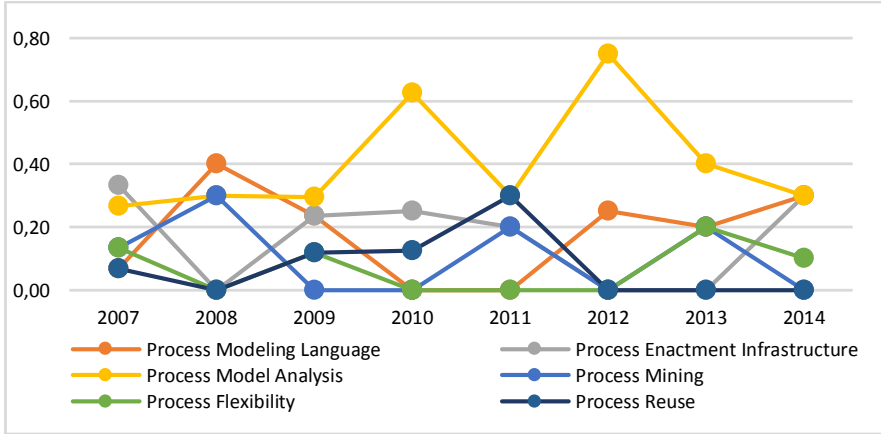

Figure 8. Importance of each concern plotted over the time in WBPM.

Grouping the concepts, the three most relevant in one hand (process modeling language, process enactment infrastructure, process model analysis) and the three others in another (process mining, process flexibility and process reuse) indicated in Figure 6, we can also perceived that they almost represent $70 \%$ of the relative importance in all years. The year 2011 is an outlier with $50 \%$ relative importance for each group and 2012 is another outlier, since the first three concerns represent $100 \%$ of the relative importance.

We are especially interested in this assembly because, according to Aalst [12], process mining, process flexibility and process reuse are concerns that are more recent, so let's call it modern group. In other hand, we have process modeling language, process enactment infrastructure and process model analysis, which are more mature concerns; hence we will call it mature group.
Our analysis indicates that those groups in Brazilian research are not in the same direction of the International Conference. Table 3 shows the sum of the relative frequencies in each group per year and Conference. Figure 9 graphically represents this difference. Comparing the earlier years of each conference with the last years, we observe that differently from the level change in International Conference which is clear, this change in the WBPM is not easily noticed.

Table 3. Importance of group of Mature Concerns and Modern Concerns over the year for each Conference.

\begin{tabular}{|c|c|c|c|c|}
\hline Year & 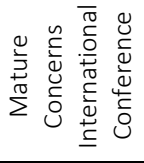 & 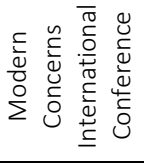 & 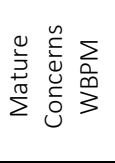 & 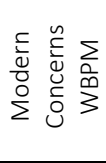 \\
\hline 2000 & 0.80 & 0.20 & & \\
\hline 2003 & 0.78 & 0.23 & & \\
\hline 2004 & 0.76 & 0.24 & & \\
\hline 2005 & 0.73 & 0.27 & & \\
\hline 2006 & 0.75 & 0.25 & & \\
\hline 2007 & 0.50 & 0.50 & 0.67 & 0.33 \\
\hline 2008 & 0.73 & 0.27 & 0.70 & 0.30 \\
\hline 2009 & 0.63 & 0.37 & 0.76 & 0.24 \\
\hline 2010 & 0.68 & 0.32 & 0.88 & 0.13 \\
\hline 2011 & 0.51 & 0.49 & 1.00 & 0.00 \\
\hline 2012 & & & 1.00 & 0.00 \\
\hline 2013 & & & 0.60 & 0.40 \\
\hline 2014 & & & 0.90 & 0.10 \\
\hline
\end{tabular}

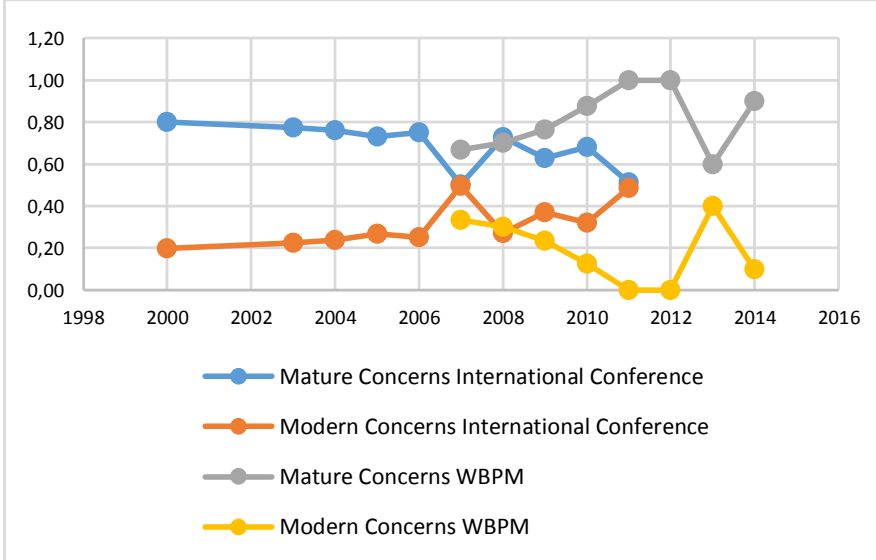

Figure 9. Importance of each group of each Conference plotted over the time.

\subsection{An Outlook through the WBPM}

Aalst analysis recognizes the "amazing speed" of the development of the BPM discipline. However, he also discusses some weaknesses. Hence, in this subsection we will take a look at the WBPM papers remarking the aspects as pointed by Aalst.

The first point is that many papers presents a new modeling language, but the need for such languages is often unclear besides they are never used again. The second point is the distance between research and real-life. Aalst believes some authors seem to focus on originality rather than relevance. The third point is about implementation. Despite the efforts, the non-availability of the software is frequent or the prototypes simply "disappear" after the publication. The result is a discontinuity of the research. Finally, in the fourthly, he noticed that many papers include case studies, which could be good, but instead they appear to be artificial and, 
often, the core contribution is not really evaluated or the case study is deliberately kept vague.

In WBPM, we noticed that the first phenomenon occurs not with languages, but with the key concern process modelling analysis. There are many papers proposing new methods, approaches or techniques, including use cases, but we did not notice the evolution or evaluation of those proposals in subsequent years. However, despite this trend, some papers reflect research continuity [34] [35] [16].

The second problem related to case studies also occurred. Often, they are used to reinforce a new technique or approach but, as Aalst criticizes in the International Conference research, they seem quite artificial.

There are few papers presenting implementations. New software is not common in WBPM. Papers tagged with the key concern process enactment infrastructure often presents a new method, technique or approach and like we noticed in the first issue, once the proposal is published there is no new publication evaluating or discussing the evolution of the proposal.

In this context, one can argue that this analysis results, lack of continuity, will occur because the natural evolution of a research, after a national publication, would be an international one. Nevertheless, we understand it is important to warn about that, because it will help to future evaluations for national conferences, publications and communities.

Although we noticed the same weakness that Aalst remarks in International Conference, we also noticed that national research is not distant from International Conference issues. Aalst recognizes that the BPM discipline has developed at a great speed and, besides that speed, in WBPM there are papers that deals with all the key concerns, the mature ones or the modern one.

Therefore, we observe that in the earliest editions we already found papers about process enactment infrastructure and process mining. Another comment is that we have publications concerned with the topic collaboration that was not evaluated in Aalst research.

Finally, we believe that WBPM contributed with the evolution of the research of the BPM field in Brazilian academy. We made a pre-analysis of all publication in the ten years of SBSI and verified that eight years of the WBPM has almost the double of papers about BPM. Now, that BPM is a main track in SBSI, we expect that research in this field will increase even more the promotion of this discipline.

\section{CONCLUSION}

In this paper, we expected to answer the research question: What are the major key concerns in Brazilian academy? We developed this research taking the same path used by Aalst [12] to evaluate the last decade of world's research in BPM, i.e., verifying the frequency of a concern in the premier Conference.

Using the papers published at WBPM, we mapped the key concerns by tagging them. Moreover, since we use Aalst research as our base, it was possible to compare the results of each Brazilian key concern's research with the International one.

The results indicate that Brazilian academy has the key concern process model analysis as its major issue and, through the eight years investigated, it has not changed at all. Moreover, this concern together with the other two most relevant concerns, process enactment infrastructure and process modelling language composes the same set of the International Conference. However, through the years, the research in the International Conference has moved to other concepts like process mining and process reuse.
Facing these results, we proposed two categories to confirm the stability of the concerns in WBPM: mature concepts and modern concepts. This category comparison made possible to conclude that the International Conference in BPM is moving from the mature concepts two the modern concepts while WBPM is not.

To recognize other state of art aspects, our research will continue in this classification direction. There are other potentially concerns: process integration, patterns, and collaboration [12] and we believe that they should be also studied. Therefore, in the next step we will address not only the increase of the scope, classifying papers of the main tracks of the Brazilian Symposium, but also try to understand these new concerns and verify its relevance for Brazilian researchers. Moreover, we believe that a use case evaluation and a perspective evaluation, like Aalst research, will help to increase this state-of-art evaluation.

Finally, with this research, we aim to start our contribution in the same manner of the original and international one [12]. As the author writes, it is a "modest attempt to guide BPM research towards the real key challenges in our field". We believe that this research will help to highlight the Brazilian research trajectory and will contribute with new research questions, e.g., Why are we in this trajectory? Which trajectory would be better? Maybe researches like that could be a baseline to move this trajectory to another one and, in the future, we can perceive this movement actualizing it. We also expect this research would influence the practitioners, and vice-versa, i.e., the practitioners with these new insights could bring new experiences and challenges to the academy.

\section{REFERENCES}

[1] M. Dumas, M. La Rosa, J. Mendling and H. A. Reijers, Fundamentals of Business Process Management, Berlin: Springer, 2013.

[2] W. Aalst, A. Hotsfede and M. Weske, "Business Process Management: a survey," in BPM 2003, Berlin Heidelberg, 2003.

[3] W. Aalst, "Business Process Management Demystified: A tutorial on models, systems and standrds for workflow management," in Lecture Notes in Computer Science, Berlin, Germany, 2004.

[4] P. Akhavan, M. Jafari and A. Ali-Ahmadi, "Exploring the interdependency between reengineering and information technology by developing a conceitual model," Business Process Management Journal, vol. 12, no. 4, pp. 517-534, 2006.

[5] R. Paim, H. Caulliraux and R. Cardoso, "Process Management Tasks: a conceptual and practical view," Business Process Management Journal, 2007.

[6] P. Fettke, P. Loos and J. Zwicker, "Business Process Reference Models: Survey and Classification," in BPM 2005 Workshops, 2005.

[7] P. Harmon, Business Process Change: A Manager's Guide to Improving, Redesigning, and Automating Processes, San Francisco: Morgan Kaufmann, 2003.

[8] J. Recker, Evaluations of Process Modeling Grammars, vol. 71, Berlin: Springer, 2011. 
[9] Gartner Group, "Gartner Group: Leading in Times of Transition: The 2010 CIO Agenda. Exp Premier Report," Gartner, Connecticut, 2010.

[10] WinterGreen Research, Inc., "WinterGreen Research: Business Process Management (BPM) Market Opportunities, Strategies, and Forecasts, 2009 to 2015.," WinterGreen Research, Lexington, 2009.

[11] M. Indulska, S. Chong, W. Bandara, S. Sadiq and M. Rosemann, "Proceeding of the 17th Australasian Conference on Information Systems.," in Australasian Association for Information Systems, Adelaide, 2006.

[12] W. M. v. d. Aalst, "Business Process Management: A Comprehensive Survey," ISRN Software Engineering, vol. 13, 2013.

[13] "I Workshop Brasileiro em Gestão de Processos em Negócios," Gramado, RS, 2007.

[14] "II Workshop Brasileiro em Gestão de Processos em Negócios," Vila Velha, ES, 2008.

[15] "III Workshop Brasileiro em Gestão de Processos em Negócios," Fortaleza,CE, 2009.

[16] "IV Workshop Brasileiro em Gestão de Processos em Negócios," Maraba, PA, 2010.

[17] "V Workshop Brasileiro em Gestão de Processos em Negócios," Salvador, BA, 2011.

[18] "VI Workshop Brasileiro em Gestão de Processos em Negócios," São Paulo, SP.

[19] "VII Workshop Brasileiro em Gestão de Processos em Negócios," 2013.

[20] "VIII Workshop Brasileiro em Gestão de Processos em Negócios," Londrina, 2014.

[21] W. M. P. v. d. Aalst, "A decade of business process management conferences: personal reflections on a developing discipline," in Proceedings of the International Conference on Business Process Management (BPM'12), Berlin, Germany, 2012.

[22] W. v. d. Aalst, J. Desel, A. Oberweis and , "Business Process Management: Models, Techniques, and Empirical Studies," in Lecture Notes in Computer Science, vol. 1806, Berlin, Germany, Springer-Verlag, 2000.

[23] W. v. d. Aalst, A. t. Hofstede, B. Kiepuszewski and A. P. Barros, "Workflow Patterns," Distributed and Parallel Databases , vol. 14, pp. 5-51, July 2003.

[24] L. Fischer, Ed., Workflow HandBook, Workflow Management Coalition. Future Strategies, Lighthouse Point, Fla, 2003.

[25] P. Lawrence, Ed., Workflow Handbook 1997, Workflow Management Coalition, New York, NY: John Wiley \& Sons, 1997.
[26] W. v. d. Aalst, Process Mining: Discovery, Conformance and Enhacement of Business Process, Berlin: Springer-Verlag, 2011.

[27] H. Schonenberg, R. Mans, N. Russel, N. Mulyar and W. M. v. d. Aalst, "Process Flexibility: A Survey of Contemporary Approaches," in Advances in Engineering I, Berlin, 2008.

[28] W. M. v. d. Aalst, M. Weske and D. Grunbauer, "Case handling: a new paradigm for business process support," in Data \& Knowledge Engineering, vol. 53, Elsevier, 2005, pp. 129-162.

[29] W. v. d. Aalst, T. Basten, H. Verbeek, P. Verkoulen and M. Voorhoeve, "Adaptive Workflow: On the interplay between flexibility and support," in Enterprise Information Systems, Springer, 2000, pp. 63-70.

[30] H. Schonenberg, R. Mans, N. Russel, N. Mulyar and W. v. d. Aalst, "Process flexibility: A survey of contemporary approaches.," in Advances in Enterprise Engineering, Springer Berlin Heidelberg, 2008, pp. 16-30.

[31] W. M. v. d. Aalst, M. Pesic and H. Schonenberg, "Declarative workflows: Balancing between flexibility and support," in Computer Science-Research and Development, vol. 23, 2009, pp. 99-113.

[32] H. Schonenberg, R. Mans, N. Russel, N. Mulyar and W. v. d. Aalst, "Process flexibility: a survey of contemporary approaches," in Advances in Enterprise Engineering I, vol. 10, J. L. Dietz, A. Albani and J. Barjis, Eds., Springer, 2008, pp. 16-30.

[33] R. Dijkman, M. La Rosa and H. Reijes, "Managing large collections of business process models: current techniques and challenges," in Computers in Industry, vol. 63, 2012, pp. 91-97.

[34] "Simpósio Brasileiro de Sistemas da Informação," Londrina, 2014.

[35] L. Thom, M. Reichert and C. Iopchpe, "On the Support of Workflow Activity Patterns in Process Modeling Tools: Purpose and requirements," 2009.

[36] W. Ugulino, R. Nunes, C. Oliveira, M. Pimentel and F. M. Santoro, "Dos processos de colaboração para as ferramentas: a abordagem de desenvolvimento do projeto CommunicaTEC.," in Companion Proceedings of the XVI Brazilian on Multimedia and the Web: II Workshop of Business Process Management, 2008.

[37] W. Ugulino and M. Pimentel, "Do As-Is para o To-Be: o método Cyclus para a melhoria de projetos de colaboração," in Proceedings of XV Braziliam Symposium on Multimedia and the Web: III Workshop of Business Process Management, Fortaleza, CE, 2009.

[38] W. Ugulino and M. Pimentel, "Melhoria de processos através da avaliação colaborativa," 2010 .

[39] W. v. d. Aast, Process Mining: Discovery, Conformance and Enhancement of Business Processes, Berlin: SpringerVerlag, 2011. 